\title{
Characteristics of Light Rail Travel Time: Examples from France
}

\author{
Jianping $W u$ \\ Mike McDonald \\ Nick Hounsell \\ University of Southampton, UK
}

\begin{abstract}
The total journey time of Light Rail Vehicles (LRVS) is made up of running time, dwell time (station stops for passenger boarding and alighting), and signal delay (delay of LRV being stopped by the regular traffic signals). Data from operational surveys of six modern light rail systems in France has shown that LRV running time was 65-71 percent of the total journey time and dwell time was 22-27 percent, while signal delay was 7 to 8 percent of the total journey time. The average operating speed of the Light Rail Transit (LRT) ranged from 17.7 to $22.8 \mathrm{~km} / \mathrm{h}$ and has an approximate linear relationship to passenger stop frequency (stops $/ \mathrm{km}$ ).

Light rail dwell time has been found to follow a log-normal distribution, although the values differed significantly between different LRT systems. The means of the dwell time distribution have the range of 16 to 31 seconds in off-peak periods and 21 to 37 seconds in peak periods. Factors that influence light rail dwell time include the number of passengers at the stops, the number of standees in the vehicles, vehicle design (number of doors, door size, low floor or high floor vehicle, etc.), fare collection system, and the location of LRT stops.

The findings in this paper could be used by LRT planners and operators directly in developing and assessing operating and service changes and in providing input to long-
\end{abstract}


range planning procedures. The results can also be used in microscopic simulation modeling studies of LRT in an urban.network, such as the TRGMSM model.

\section{Introduction}

Light rail systems are increasingly being considered as an effective and environmentally friendly alternative to alleviate urban congestion problems in $\mathrm{Eu}$ ropean and North American cities. Throughout the world, there are more than 300 urban light rail or tramway systems in operation (Department of Transport 1995, Bushell 1993).

The operating speed, dwell time (station stops for passenger boarding and alighting), and signal delay (delay of light rail vehicles being stopped by the regular traffic signals) of light rail vehicles (LRVs) directly contribute to journey time and affect the number of vehicles required to operate a given time table. Beyond this obvious effect, these parameters may govern the line capacity in the system because of the on-line stations (stops) and the lack of overtaking (passing) opportunities. Further, the parameter dwell time is generally accepted to be the major factor causing vehicle bunching in segregated systems, which, in turn, results in variability in headways. Headway variability itself results in higher than necessary passenger journey times and uneven vehicle passenger loads, both of which influence the attractiveness of the service.

Despite their importance, relatively few studies have been done to quantify these parameters. Lin and Wilson (1992) and Fritz (1983) explored the characteristics of light rail dwell time. However, their work was based on a limited survey and considered only dwell time. Levinson (1983) investigated the operation characteristics that included operating speed, dwell time and signal delay on the operation of bus systems in a cross-section of U.S. cities. His work provided useful relationships and parameters to public transport engineers for planning of service changes and impact analysis of bus systems

In the last few years, several LRT systems have been constructed in France (Paris, Strasbourg, and Rouen), and others are under construction (Urban Net- 
work News 1994). To understand the travel time characteristics of modern LRT systems, six existing LRT systems in France were surveyed in early 1995. In this paper, analyses of LRT total journey time, operating speed, signal delay, and dwell time were carried out based on the survey. The results presented may be used by.LRT operators, planners, and engineers for light rail systems planning, design, and simulation studies.

To help readers understand and review the terms used in this paper, definitions are provided in Appendix A.

\section{The Light Rail Systems}

The six light rail systems investigated are those located in Grenoble, Lille, Strasbourg, Nantes, Paris, and Rouen. Most of these light rail systems operate atgrade and are either totally or mostly segregated from the normal road vehicles. Underground running is used in Lille, Strasbourg, and Rouen when light rail passes through the railway station and busy commercial areas. Flyovers were found in Grenoble, Rouen, and Paris where light rail crosses roads with heavy traffic in the suburban areas. The general characteristics of these light rail systems are summarized in Table 1, and the main operating characteristics are summarized in Table 2.

Four of the six LRT systems (Grenoble, Lille, Paris and Rouen) use fourdoor, low-floor light rail vehicles, although they are of different designs and capacities. The Strasbourg LRT uses six-door,-low-floor vehicles, while the Nantes LRT uses eight-door vehicles with only the middle two doors being low-floor. All these LRVs allowed two-way movements (alighting and boarding) of passengers in each door and operated with the same rolling stock through the day (no difference between peak and off-peak period services). All the LRT systems were equipped with self-service ticketing machines at the stops. In Grenoble, Lille, Nantes, and Strasbourg, passengers validate their tickets in machines at the light rail stops, whereas, in Rouen and Paris, in-vehicle ticket validating machines were used.

For the Grenoble and Lille systems, each ticket was valid for one journey in the same direction regardless of the journey length. However, in Nantes, Paris, 
Table 1

\section{General Infórmation of the Light Rail Systems}

\begin{tabular}{|c|c|c|c|c|c|}
\hline \multirow[t]{2}{*}{ LRT Systems } & \multirow{2}{*}{$\begin{array}{l}\text { Line } \\
\text { Length } \\
(\mathrm{km})\end{array}$} & \multirow{2}{*}{$\begin{array}{l}\text { Passenger } \\
\text { Stops }\end{array}$} & \multicolumn{3}{|c|}{ LRV Capacity (persons) } \\
\hline & & & Seats & Standees & Total \\
\hline $\begin{array}{l}\text { Grenoble LRT Line B } \\
\text { (PI De La Gare-Universitaire) }\end{array}$ & 5.9 & 14 & 46 & 134 & 180 \\
\hline $\begin{array}{l}\text { Lille LRT Line I } \\
\text { (Roubaix-Gare Lille Flandres) }\end{array}$ & 10.0 & 23 & 74 & 269 & 343 \\
\hline $\begin{array}{l}\text { Nantes LRT Line } 2 \\
\text { (Trocardiere-Orvault Grand Val) }\end{array}$ & 14.0 & 30 & 50 & 195 & 245 \\
\hline $\begin{array}{l}\text { Paris LRT Line } \\
\text { (Saint Denis-Bobigny-Pablo Picasso) }\end{array}$ & 9.0 & 21 & 52 & 126 & 178 \\
\hline $\begin{array}{l}\text { Rouen LRT Line } \\
\text { (Georges Braque-Boulingrin- } \\
\text { Sotteville) }\end{array}$ & 11.0 & 22 & 52 & 126 & 178 \\
\hline $\begin{array}{l}\text { Strasbourg LRT Line } \\
\text { (Baggersee-Hautepierre Maillon) }\end{array}$ & 10.0 & 18 & 66 & 201 & 267 \\
\hline
\end{tabular}

*: $\quad$ Including the start and end terminus.

\begin{tabular}{|c|c|c|c|c|c|}
\hline \multicolumn{6}{|c|}{$\begin{array}{l}\text { Table } 2 \\
\text { Main Operation Characteristics of the LRT Systems }\end{array}$} \\
\hline \multirow[t]{2}{*}{ LRT Systems } & \multicolumn{2}{|c|}{$\begin{array}{c}\text { Degree of Segregation of } \\
\text { Operation }\end{array}$} & \multicolumn{3}{|c|}{ Junction Crossing Types } \\
\hline & City Centre & Suburban & At Grade & Underground & Flyover \\
\hline Grenoble LRT Line B & Mixed Operation & Segregated & Most & None & One \\
\hline Lille LRT Line 1 & Separated & Segregated & Most & City Centre & None \\
\hline Nantes LRT Line 2 & Segregated & Segregated & All & None & None \\
\hline Paris LRT Line & $\begin{array}{l}\text { Some Area } \\
\text { Shared with } \\
\text { Buses }\end{array}$ & Segregated & Most & None & One \\
\hline Rouen LRT Line & Separated & Segregated & Most & City Centre & One \\
\hline Strasbourg LRT Line & Separated & Segregated & Most & City Centre & None \\
\hline
\end{tabular}

Rouen, and Strasbourg, one ticket, validated in a ticket validating machine, could be used for one hour for all routes.

Light rail stations/stops may be classified into three categories: upstream stops (LRT stops located upstream of the stop line at traffic-signal-controlled intersections), downstream stops (LRT stops downstream of the stop line at traffic signal controlled intersections) and middle-block stops (LRT stops located in 
the middle area between two traffic-signal-controlled intersections) according to their location relative to intersections. Most frequently, the upstream and downstream stations are used when light rail runs in the central area, where both normal road traffic and light rail passenger flows are high. Middle-block stops were found mostly in suburban areas, where normal road traffic flow are not very high and light rail can run at higher speeds.

\section{The Operational Surveys}

The operational surveys were preceded by the collection of information on LRT routes and timetables from the local transportation authorities. A general survey of the LRT characteristics was carried out, covering the LRT line (name of the line, line length, type of operation/degree of segregation of rail track, total number of passenger stops and traffic intersections), LRVs (designed capacity, door configuration, fare collecting system, rolling stock), LRT stations/stops (locations, layouts, information and ticketing systems), intersections (type of intersection, type of crossing -at-grade or grade separated, type of signal control, and priority). A photographic record also was taken for subsequent reference.

During the operational survey, the surveyor in the vehicle recorded the time of LRV departure from the terminus, the wheel stop and start times for each LRV stop, and the reasons for stopping (e.g., stop at passenger stops, stop at signalised traffic intersections). Surveys were carried out during weekdays twice in peak periods (4:00 p.m.-6:00 p.m.) and twice in off-peak periods (10:30 a.m.-12:30 p.m.) for each light rail system.

\section{Analysis and Results}

In the following analysis, peak refers to the average value of the two surveys in peak time, off-peak refers to the average value of the two surveys in offpeak time, and average refers to the average value of peak and off-peak.

\section{Journey Time}

The time when a vehicle left the start terminus to when it arrived at the end terminus is defined as the total journey time. Thè peak, off-peak, and average journey times of the six light rail systems are listed in Table 3 . The average jour- 
Table 3

LighțRail Total Journey Time

\begin{tabular}{|c|c|c|c|c|c|}
\hline \multirow[t]{2}{*}{ LRT Systems } & \multirow{2}{*}{$\begin{array}{l}\text { Line Length } \\
\quad(\mathrm{km})\end{array}$} & \multicolumn{3}{|c|}{ Total Journey Time (minutes) } & \multirow{2}{*}{$\begin{array}{c}\text { Differences } \\
\text { Between Peak and } \\
\text { Off-Peak } \\
(\%) \\
\end{array}$} \\
\hline & & Peak & Off-Peak & Average & \\
\hline Grenoble LRT & 5.9 & 20.0 & 19.0 & 19.5 & 5 \\
\hline Lille LRT & 10.0 & 36.0 & 32.0 & 34.0 & .11 \\
\hline Nantes LRT & 14.0 & 48.0 & 43.0 & 45.5 & 12 \\
\hline Paris LRT & 9.0 & 35.5 & 32.5 & 34.0 & 9 \\
\hline Rouen LRT & 11.0 & 34.0 & 32.0 & 33.0 & 6 \\
\hline Strasbourg LRT & 10.0 & 31.0 & 29,0 & 30.0 & 6 \\
\hline
\end{tabular}

ney time was found to vary between a minimum of 19.5 minutes (Grenoble) and a maximum of 45.5 minutes (Nantes). The difference in total journey times between peak and off-peak varied between 5 percent (Grenoble) and 12 percent (Nantes). While total journey time is not a very useful indicator of operational characteristics because it is mainly controlled by LRT line lengths, the percentage of each component of the LRT total journey time may be considered to reflect its operation efficiency and service quality.

Light rail journey time consists of three parts, running time, dwell time, and delay caused by traffic signals. The results shown in Figures 1 and 2 indicate that signal delay took 7 to 8 percent of light rail total journey time, dwell time 22 to 27 percent, and running time 65 to 71 percent for the six surveyed light rail systems. Detailed discussions on LRT operating speed, running time/speed, signal delay, and dwell time are contained in the following sections.

\section{Operating Speed}

Operating speed, which is calculated by dividing the light rail line length by total journey time, is an important index of LRT operation and service quality, since it removes the influence of LRT line length. Unlike total journey time, light rail operating speeds showed much less variation between lines, ranging from $17.71 \mathrm{~km} / \mathrm{h}$ in Lille to $20.02 \mathrm{~km} / \mathrm{h}$ in Rouen and Strasbourg (see Table 4). The difference in operating speed between peak and off-peak periods varied between 


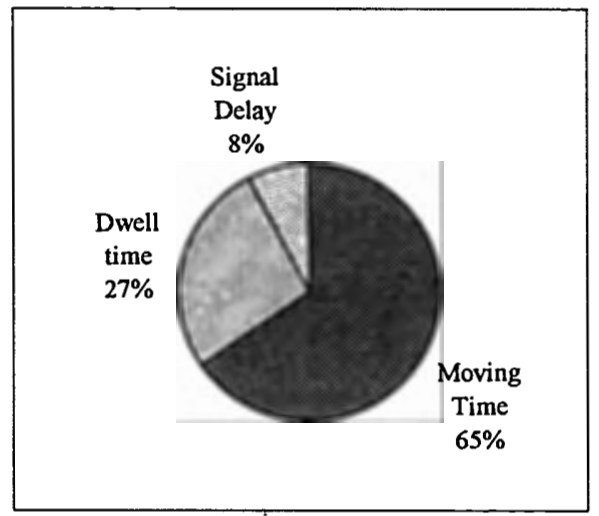

Figure 1. Composition of total journey time (peak time).

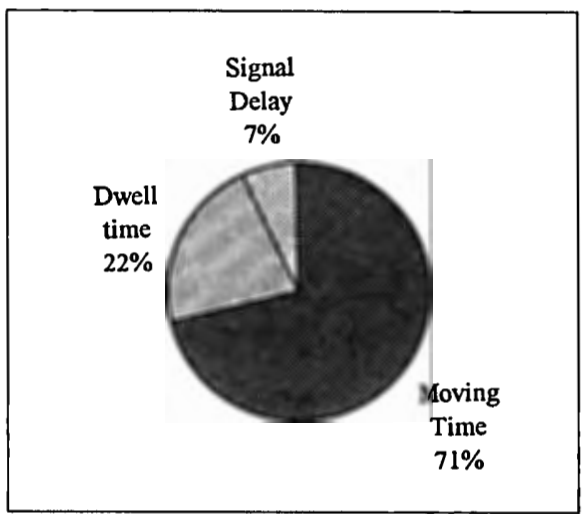

Figure 2. Composition of total journey time (off-peak time).

\begin{tabular}{|l|c|c|c|c|}
\hline \multicolumn{7}{|c|}{ Light Rail Operating Speed } \\
\hline \multirow{2}{*}{ LRT Systems } & \multicolumn{5}{c|}{ Average Operating Speed $(\mathrm{km} / \mathrm{h})$} & $\begin{array}{c}\text { Difference Between } \\
\text { Peak and Off-Peak }\end{array}$ \\
\cline { 2 - 5 } & Peak & Off-Peak & Average & $(\%)$ \\
\hline Grenoble LRT & 17.70 & 18.63 & 18.17 & 5 \\
\hline Lille LRT & 16.67 & 18.75 & 17.71 & 13 \\
\hline Nantes LRT & 17.50 & 19.67 & 18.59 & 12 \\
\hline Paris LRT & 15.21 & 16.62 & 15.92 & 9 \\
\hline Rouen LRT & 19.41 & 20.63 & 20.02 & 7 \\
\hline Strasbourg LRT & 19.35 & 20.69 & 20.02 & \\
\hline
\end{tabular}

different light rail systems. The Grenoble, Rouen, and Strasbourg LRTs had a 5 to 7 percent difference in operating speed between peak and off-peak periods, while the Nantes and Lille LRTs had differences of up to 12 to 13 percent.

Many factors may have affected light rail operating speeds. A main factor may be the frequency of passenger stops; as shown in Figures 3 and 4, light rail operating speeds decreased as the number of passenger stops increased for both the peak and off-peak periods. Appropriate linear relationships have been found between the operating speeds and the average frequency of passenger stops for both peak and off-peak periods by regression analysis (Manugistics 1992) with the general forms as below: 


$$
\begin{array}{lc}
Y=30.08-5.76^{*} \mathrm{X} & \left(\text { Peak Time with } \mathrm{R}^{2}=0.64\right) \\
\mathrm{Y}=31.27-5.61 * \mathrm{X} & \because\left(\text { Off-Peak Time with } \mathrm{R}^{2}=0.68\right)
\end{array}
$$

where $\mathrm{X}$ is the average frequency of passenger stops (stops $/ \mathrm{km}$ ) and $\mathrm{Y}$ is light rail operating speed $(\mathrm{km} / \mathrm{h})$.

\section{LRV Running Time and Running Speed}

The percentage of running time out of the total journey time may be taken as an index of LRT operation efficiency. It was shown in Figures 1 and 2 that light rail's running time was approximately two-thirds of the total journey time,

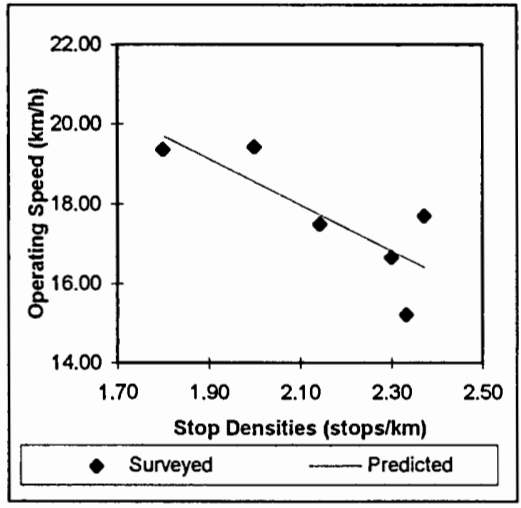

Figure 3. Operating speed and stop frequency (peak periods).

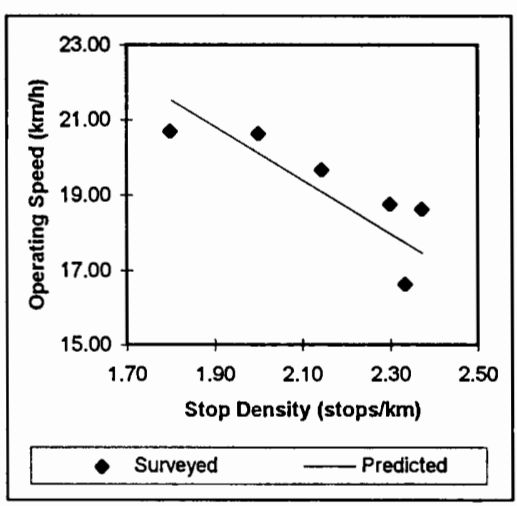

Figure 4. Operating speed and stop frequency (off-peak periods).

with a 6 percent difference between peak and off-peak for the surveyed light rail systems.

The differences in runining times as a percentage of total journey times between different light rail systems are shown in Table 5. The minimum running time share was 58 percent in Paris, and the maximum was 74 percent in Rouen. Significant differences between peak and off-peak periods were also found in some light rail systems, e.g. 20 percent in Nantes and 14 percent in Lille. 


\begin{tabular}{|l|c|c|c|c|}
\hline \multicolumn{5}{|c|}{ Table 5 } \\
LRV Running Time \\
\hline \multirow{2}{*}{ LRT Systems } & \multicolumn{3}{c|}{$\begin{array}{c}\text { Running Time in Percentage of } \\
\text { Total Journey Time (\%) }\end{array}$} & $\begin{array}{c}\text { Difference Between Peak } \\
\text { and Off-Peak }\end{array}$ \\
\cline { 2 - 5 } & Peak & Off-Peak & Average & $(\%)$ \\
\hline Grenoble LRT & 69.45 & 75.11 & 72.28 & 8.14 \\
\hline Lille LRT & 61.39 & 69.91 & 65.65 & 13.87 \\
\hline Nantes LRT & 61.98 & 74.60 & 68.29 & 20.36 \\
\hline Paris LRT & 59.72 & 56.62 & 58.17 & -5.19 \\
\hline Rouen LRT & 71.56 & 77.38 & 74.47 & 8.13 \\
\hline Strasbourg LRT & 67.32 & 70.62 & 68.97 & 4.90 \\
\hline
\end{tabular}

Running speed is defined as the ratio of the light rail line length to its running time. As shown in Table 6, this differs between different light rail systems with a minimum of $25 \mathrm{~km} / \mathrm{h}$ in Grenoble LRT and a maximum of $29 \mathrm{~km} / \mathrm{h}$ in Strasbourg LRT. The differences between peak and off-peak periods were insignificant for most of the LRT systems except for the Paris LRT, where the difference was as high as 13 percent.

The factors that may influence running speed include the degree of segregation (e.g., mixed, segregated, or separated operation), vehicle acceleration and deceleration capabilities, maximum cruise speed, and driver characteristics. For example, in Grenoble, the LRT shares the road space with other road traffic (mixed operating) in the city area. The movement of LRV is sometimes impeded by

\begin{tabular}{|c|c|c|c|c|}
\hline \multicolumn{5}{|c|}{$\begin{array}{c}\text { Table } 6 \\
\text { LRV Running Speed }\end{array}$} \\
\hline \multirow[t]{2}{*}{ LRT Systems } & \multicolumn{3}{|c|}{ Average Light Rail Running Speed $(\mathrm{km} / \mathrm{h})$} & $\begin{array}{c}\text { Difference Between Peak } \\
\text { and Off-Peak }\end{array}$ \\
\hline & Peak & Off-Peak & Average & (\%) \\
\hline Grenoble LRT & 25.49 & 24.81 & 25.14 & 3 \\
\hline Lille LRT & 27.15 & 26.82 & 26.99 & 1 \\
\hline Nantes LRT & 28.24 & 26.18 & 27.21 & 8 \\
\hline Paris LRT & 25.47 & 29.35 & 27.41 & -13 \\
\hline Rouen LRT & 27.13 & 26.66 & -26.89 & 2 \\
\hline Strasbourg LRT & 28.75 & 29.30 & 29.02 & -2 \\
\hline
\end{tabular}


pedestrians and other road vehicles, reducing the LRT running speed. However, in Strasbourg, the LRT uses segregated right-of-way for the whole line, with underground running in the central area. A higher LRV running speed $(29 \mathrm{~km} / \mathrm{h})$ was therefore recorded.

\section{Signal Delay}

Although the average delay at traffic signals constituted only 7 to 8 percent of the total journey time, as shown in Figures 1 and 2, the differences were significant between different light rail systems. It may be seen from Table 7 that the signal delay of LRVs in Lille was about 18 percent of the total journey time, while no signal delay was observed in the Strasbourg LRT in peak period. In the off-peak, Paris LRT had the highest signal delay of 14 percent of the total journey time, while the Strasbourg LRT had only 1 percent. Differences between peak and off-peak periods were found to be very significant for some light rail systems. For example, the peak-period signal delay was about twice as high as that in off-peak time for the Lille and Nantes LRTs.

The amount of signal delay depends predominantly on the density of signalcontrolled intersections, the form of signal control and the priority measures for the LRT vehicles. Providing high priority to light rail vehicles can significantly increase operating speeds. For example, for the six light rail systems studied, if a full signal priority had been assigned (no signal delays for all the light rail systems), an average increase in operating speed would be from 1 to 16 percent,

\begin{tabular}{|l|c|c|c}
\hline \multicolumn{3}{|c|}{$\begin{array}{c}\text { Table 7 } \\
\text { LRV Signal Delay }\end{array}$} \\
\hline \multicolumn{1}{|c|}{ LRT Systems } & \multicolumn{3}{c}{ Signal Delay in Percentage of Total Journey Time (\%) } \\
\cline { 2 - 4 } & Peak & Off-Peak & Average \\
\hline Grenoble LRT & 8.00 & 8.47 & 8.24 \\
\hline Lille LRT & 18.03 & 8.63 & 13.33 \\
\hline Nantes LRT & 6.77 & 3.47 & 5.12 \\
\hline Paris LRT & 9.77 & 13.97 & 11.87 \\
\hline Rouen LRT & 3.88 & 5.88 & 4.88 \\
\hline Strasbourg LRT & 0.00 & 1.10 & 0.55 \\
\hline
\end{tabular}


varying between systems as shown in Table 8. Furthermore, according to a study by Wu and McDonald (1996), high priority for LRVs can significantly reduce delay at signalled intersections without necessarily causing significant extra delay to non-priority vehicles.

Table 8

Operating Speed and Signal Delay

\begin{tabular}{l|c|c|c|c|c|c|c}
\hline \multirow{2}{*}{ LRT Systems } & \multicolumn{2}{|c|}{$\begin{array}{c}\text { Operating Speed } \\
\text { Without Signal Delay } \\
(\mathrm{km} / \mathrm{h})\end{array}$} & \multicolumn{2}{|c|}{$\begin{array}{c}\text { Operating Speed } \\
\text { As They Were } \\
(\mathrm{km} / \mathrm{h})\end{array}$} & \multicolumn{3}{|c}{$\begin{array}{c}\text { Operating Speed Increase When } \\
\text { Without Signal Delay } \\
(\%)\end{array}$} \\
\cline { 2 - 8 } & Peak & Off-Peak & Peak & Off-Peak & Peak & Off-Peak & Average \\
\hline Grenoble LRT & 19.24 & 20.76 & 17.70 & 18.63 & 8.7 & 9.26 & 8.98 \\
\hline Lille LRT & 20.33 & 20.52 & 16.67 & 18.75 & 21.99 & 9.44 & 15.72 \\
\hline Nantes LRT & 18.77 & 20.24 & 17.50 & 19.53 & 7.26 & 3.59 & 5.43 \\
\hline Paris LRT & 16.86 & 19.31 & 15.21 & 16.62 & 10.83 & 16.24 & 13.54 \\
\hline Rouen LRT & 22.20 & 21.91 & 19.41 & 20.63 & 4.04 & 6.24 & 5.14 \\
\hline Strasbourg LRT & 19.35 & 20.92 & 19.35 & 20.69 & 0.00 & 1.12 & 0.56 \\
\hline
\end{tabular}

\section{Dwell Time}

Generally, the percentage of dwell time (or station stops for passenger boarding and alighting) had an average of 22 to 27 percent of the total journey time, as shown in Figures 1 and 2. However, this varied significantly between different systems. As shown in Table 9, the average dwell time per stop was only 14.4 seconds in the Grenoble LRT, but was 28.9 seconds in Strasbourg during the off-

\begin{tabular}{|c|c|c|c|c|}
\hline \multicolumn{5}{|c|}{$\begin{array}{c}\text { Table } 9 \\
\text { LRT Dwell Time }\end{array}$} \\
\hline \multirow[t]{2}{*}{ LRT Systems } & \multicolumn{3}{|c|}{$\begin{array}{l}\text { Mean Dwell time Per Stop } \\
\text { (seconds) }\end{array}$} & $\begin{array}{c}\text { Difference Between Peak and } \\
\text { Off-Peak }\end{array}$ \\
\hline & Peak & Off-Peak & Average & \begin{tabular}{|c|}
$(\%)$ \\
\end{tabular} \\
\hline Grenoble LRT & 20.82 & 14.40 & 17.61 & 44.55 \\
\hline Lille LRT & 20.21 & 18.74 & 19.47 & 7.86 \\
\hline Nantes LRT & 31.03 & 19.51 & 25.27 & 59.07 \\
\hline Paris LRT & 32.49 & 28.68 & 30.59 & 13.28 \\
\hline Rouen LRT & 23.86 & 15.31 & $19: 59$ & 55.78 \\
\hline Strasbourg LRT & 35.75 & 28.94 & 32.35 & 23.54 \\
\hline
\end{tabular}


peak. In the peak hour, the Strasbourg LRT had an average dwell time of 35.8 seconds per stop, but this was.only 20.2 seconds in Lille. Significant differences in dwell time were also found for some light rail systems between peak and offpeak periods. For example, in the Grenoble, Nantes, and Rouen LRTs, the differences were 45 to 59 percent.

\section{Factors Affecting Light Rail Dwell Time}

During the light rail operation survey, several factors were observed to influence dwell time.

- Little difference was seen between the dwell times for one passenger and three or four passengers because of the multiple, wide, two-way (alighting and boarding) door systems and the low-floor vehicles used.

- As the number of standees near the doorway increased, the time of alighting or boarding per passenger increased significantly. This occurred particularly when there was an .in-vehicle ticket validating machine near the door.

- One unpredictable element on LRV dwell time is the driver's characteristics. The time from LRV wheel stop to door open and the time of last passenger boarding to door closure/wheel start was observed to vary from driver to driver.

\section{LRT Dwell Time Models Review}

Previous work on vehicle dwell times (or the related measure, passenger service times) has been focused on bus systems, with relatively little attention paid to light rail systems. Typically, least squares regression has been used to relate vehicle dwell time to the numbers of passengers boarding and alighting, with separate models estimated for different operating characteristics likely to affect dwell time, such as the restriction on door usage for boarding and alighting, fare collection method, door configuration, and high-floor or low-floor vehicle (Leivine et al. 1994; Marshall et al. 1990; Guenthner and Sinha 1983; Zografos and Levinson 1986; Levinson 1983; Guenthner and Hamat 1988; Ceder and Marguier 1985; Kraft and Deutschman 1977; Cundill and Watts 1973). 
Lin and Wilson (1992) and Fritz (1983) suggested that models for light rail transit for the Green Line of Massachusetts Bay Transportation Authority (MBTA) were similar to the bus dwell time models described above. These LRT dwell time models, either linear or non-linear, simply related the light rail dwell time to the number of passengers alighting, boarding, and present on the vehicle. Also, as these dwell time models were developed from only one light rail line survey, it is unlikely that they can be used more generally for other modern light rail systems because of the differences on LRV capacity, door configuration, fare collection system, etc.

It was beyond the scope of this study to collect a rigorous and comprehensive data set capable of finding an adequate database for multivariable analysis. It was therefore decided to investigate the distribution of LRV dwell times at stops and identify any significant differences between lines/stops using appropriate statistical analysis. This work is described in the following section.

\section{The Distribution of LRT Dwell Time}

The differences in LRT dwell time were found to be significant from LRT system to system, stop to stop and time to time. However, a statistical analysis of these results indicates that LRT dwell time followed a log-normal distribution which has a general form of:

$$
f(x)=\frac{1}{x \sigma \sqrt{2 \pi}} \exp \left(-\frac{(\ln (x)-\mu)^{2}}{2 \sigma^{2}}\right)
$$

where $\mu$ is the mean and $\sigma$ is the standard deviation. Figure 5 shows a typical distribution of LRT dwell time; Table 10 lists the sample sizes of LRT dwell time data, which were used in the statistical analyses for the six surveyed LRT systems.

The K-S (Kolmogorov-Smirnov) test (Manugistics 1992) results of the overall goodness-of-fit between the LRT dwell time and the theoretical (log-normal) distribution for all the six LRT systems are shown in Table 11. It shows in the table that the significance levels of K-S test for all the six LRT systems are significantly greater than 0.05 , which indicates a goồ fit of the LRT dwell time to the theoretical log-normal distribution. 


\begin{abstract}
Although a more complex causal relationship for dwell time could not be developed, given the data available in this study, the main factors that result in the variance of the LRT dwell time are discussed in following sections.
\end{abstract}

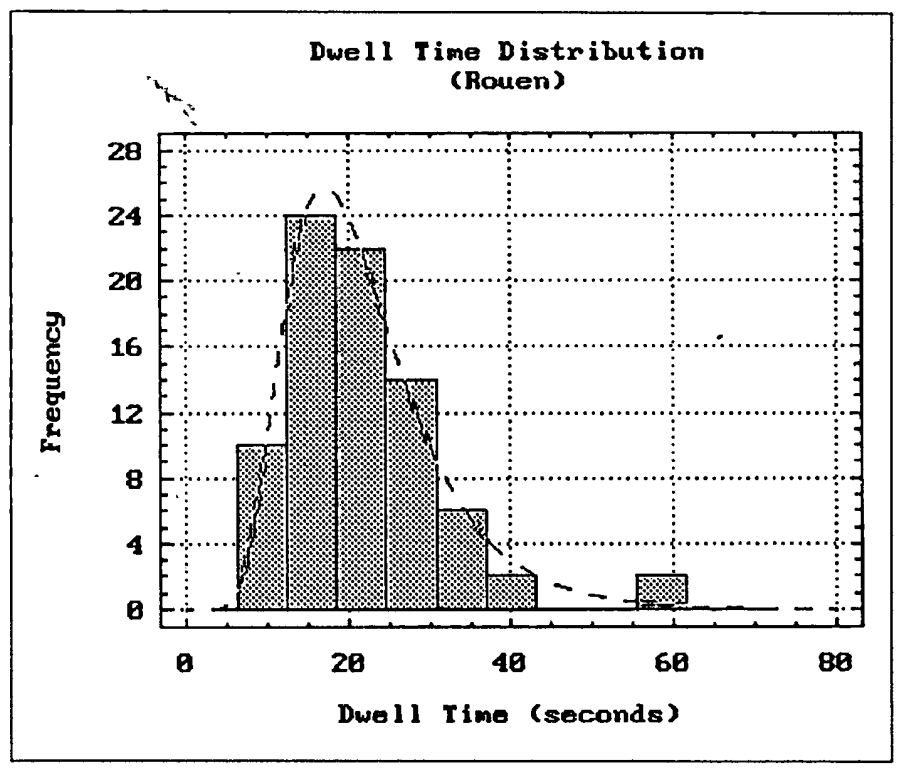

Figure 5. Example of LRT dwell time distribution.

\begin{tabular}{|l|c|c|c|}
\hline \multicolumn{4}{|c|}{ Table 10} \\
Sample of Sizes of LRT Dwell Time Data \\
\hline LRT Systems & \multicolumn{3}{c|}{ Sample Size } \\
\cline { 2 - 4 } & Peak & Off-Peak & Total \\
\hline Grenoble LRT & 28 & 28 & 56 \\
\hline Lille LRT & 46 & 46 & 92 \\
\hline Nantes LRT & 60 & 60 & 120 \\
\hline Paris LRT & 42 & 42 & 84 \\
\hline Rouen LRT & 44 & 44 & 88 \\
\hline Strasbourg LRT & 36 & 36 & 72 \\
\hline
\end{tabular}

\title{
Difference Between Different LRT Systems
}

Although LRT dwell time follows a log-normal distribution, a significant difference was found between different LRT systems. Figure 6 shows the difference in the parameters $\mu$ (mean) and $\sigma$ (standard deviation) between the different LRT systems.

Two sample K-S tests were carried out to assess the overall difference of LRT dwell time between different LRT systems. The results shown in Table 12 
Table 11

\section{K-S Test Results for Log-Normal Distribution}

\begin{tabular}{l|c|c}
\hline Dwell Time Data & Significance Level of K-S Test & Significant Fit \\
\hline Grenoble & 0.541 & $\sqrt{ }$ \\
Lille & 0.506 & $\sqrt{ }$ \\
Nantes & 0.248 & $\sqrt{ }$ \\
Paris & 0.513 & $\sqrt{ }$ \\
Rouen & 0.243 & $\sqrt{ }$ \\
Strasbourg & 0.273 & $\sqrt{ }$ \\
\hline
\end{tabular}

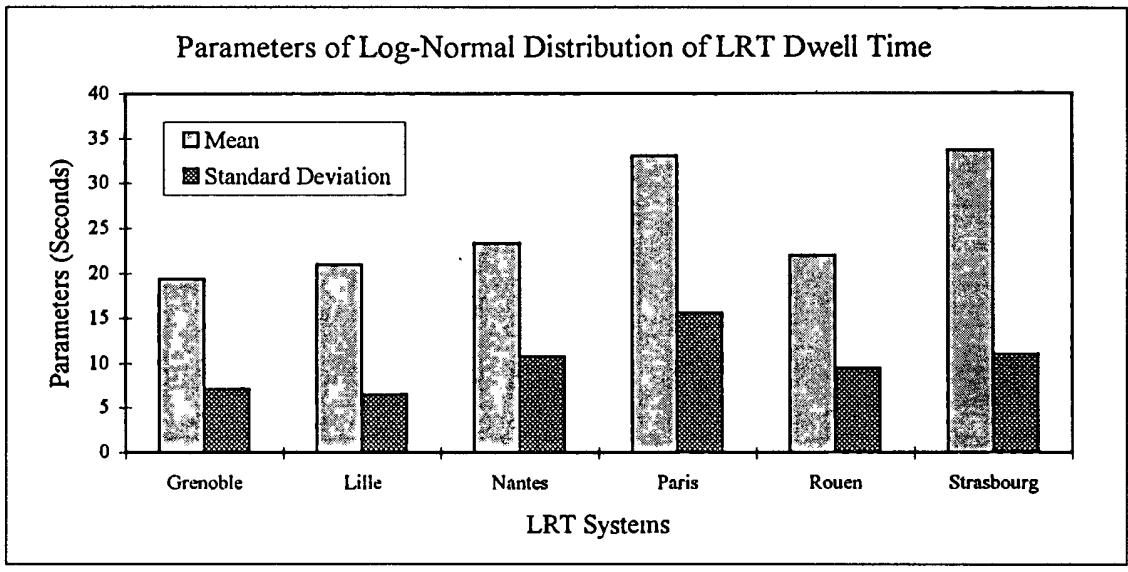

Figure 6. Difference on parameters $\mu$ (mean) and $\sigma$ (standard deviation) between different LRT systems.

indicate that significant differences exist for most of the compared pairs, as shown by a K-S significance level of less than 0.05 .

\section{Difference Between Peak and Off-Peak Time}

The difference in LRT dwell times between peak and off-peak periods is also significant, except for the Lille and Strasbourg LRTs (with K-S significance level test results greater than 0.05 ). Results are shown in Table 13.

\section{Parameters for LRT Dwell Time Models}

Table 14 summarizes the parameters, $\mu$ (meañ) and $\sigma$ (standard deviation), of the log-normal distribution for each of the LRT systems studied under both 


\begin{tabular}{|c|c|c|}
\hline \multicolumn{3}{|c|}{ Table 12} \\
\hline LRT Systems & $\begin{array}{l}\text { Approximate Significance Level of } \\
\text { Two Sample K-S Test }\end{array}$ & Significantly Different \\
\hline Grenoble --- Lille & $2.05 \mathrm{E}-2$ & $\sqrt{2}$ \\
\hline Grenoble -...- Nantes & $5.35 \mathrm{E}-2$ & $\mathrm{X}$ \\
\hline Grenoble - Paris & $4.86 E-7$ & $\sqrt{ }$ \\
\hline Grenoble $\cdots \cdots$ Rouen & $6.01 \mathrm{E}-2$ & $\mathrm{x}$ \\
\hline Grenoble - - Strasbourg & 0.00 & $\sqrt{ }$ \\
\hline Lille -..- Nantes & 4.11E-2 & $\sqrt{1}$ \\
\hline Lille -..... Paris & $4.24 E-8$ & $\sqrt{1}$ \\
\hline Lille - Rouen & $2.53 \mathrm{E}-2$ & $\checkmark$ \\
\hline Lille -...- Strasbourg & 0.00 & $\sqrt{ }$ \\
\hline Nantes …- Paris & $3.19 E-6$ & $\sqrt{ }$ \\
\hline Nantes $\ldots$ Rouen & $9.60 \mathrm{E}-2$ & $\mathrm{x}$ \\
\hline Nantes $-\ldots$ Strasbourg & 0.00 & $\sqrt{ }$ \\
\hline Paris --.-- Rouen & $8.32 E-3$ & $\sqrt{ }$ \\
\hline Paris --- Strasbourg & $9.62 E-9$ & $\sqrt{ }$ \\
\hline Rouen --..-- Strasbourg & $7.76 E-9$ & $\sqrt{ }$ \\
\hline
\end{tabular}

\begin{tabular}{|l|c|c|}
\hline \multicolumn{3}{|c|}{ Table 13 } \\
Two Sample K-S Tests of LRT Dwell Time Between Peak and Off-Peak Period \\
\hline \multicolumn{1}{|c|}{ LRT Systems } & $\begin{array}{c}\text { Approximate Significance Level of } \\
\text { Two Sample K-S Test }\end{array}$ & Significantly Different \\
\hline Grenoble & $7.87 E-4$ & $\checkmark$ \\
\hline Lille & $3.03 \mathrm{E}-1$ & $\mathrm{X}$ \\
\hline Nantes & $6.80 E-3$ & $\checkmark$ \\
\hline Paris & $2.82 E-3$ & $\checkmark$ \\
\hline Rouen & $1.68 \mathrm{E}-2$ & $\checkmark$ \\
\hline Strasbourg & $1.59 \mathrm{E}-1$ & $\mathrm{X}$ \\
\hline
\end{tabular}

peak and off-peak periods. The mean, $\mu$, of LRT dwell time has a range of 16 to 31 seconds in off-peak period and 22 to 37 seconds in peak period. The LRT dwell time models together with the parameters in Table 14 may be used as reference for LRT system operation analysis and LRT network simulation modeling study.

Dwell time is an important factor influencing light rail operating speeds. It may be seen from Table 15 that if a dwell time of 5 seconds could be saved at each stop, the operating speed for the light rail systems would increase by about 5 to 6 percent on average. 


\section{Table 14}

\section{Log-Normal Distribution Parameters of LRT Dwell Time in Peak and Off-Peak Periods}

\begin{tabular}{l|c|c|c|c}
\hline \multicolumn{1}{c|}{ LRT Systems } & \multicolumn{2}{|c|}{ Parameters in Peak Period } & \multicolumn{2}{c}{ Parameters in Off-Peak Period } \\
\hline & $\mu$ (mean) & $\sigma$ (Standard Deviation) & $\mu$ (mean) & $\sigma$ (Standard Deviation) \\
\hline Grenoble & 22.994 & 7.728 & 15.738 & 4.655 \\
\hline Lille & 21.896 & 7.162 & 19.977 & 5.793 \\
\hline Nantes & 26.642 & 12.783 & 20.102 & 8.129 \\
\hline Paris & 35.259 & 14.628 & 30.787 & 15.912 \\
\hline Rouen & 24.602 & 12.017 & 19.463 & 6.662 \\
\hline Strasbourg & 36.805 & 13.253 & 30.646 & 8.404 \\
\hline
\end{tabular}

Table 15

Increase on Operating Speed When with 5 Seconds Dwell Time Savings

\begin{tabular}{l|c|c|c|c|c|c|c}
\hline LRT Systems & \multicolumn{2}{|c|}{$\begin{array}{c}\text { Operating Speed With } \\
\text { Dwell Time Saving } \\
(\mathrm{km} / \mathrm{h})\end{array}$} & \multicolumn{2}{|c|}{$\begin{array}{c}\text { Operating Speed } \\
\text { Without Dwell Time } \\
\text { Saving }\end{array}$} & \multicolumn{3}{|c}{$\begin{array}{c}\text { Operating Speed Increase With } \\
\text { Dwell Time Saving } \\
(\%)\end{array}$} \\
\hline & Peak & Off-Peak & Peak & Off-Peak & Peak & Off-Peak & Average \\
\hline Grenoble LRT & 18.80 & 19.85 & 17.70 & 18.63 & 5.83 & 6.14 & 5.99 \\
\hline Lille LRT & 17.60 & 19.94 & 16.67 & 18.75 & 5.32 & 5.99 & 5.65 \\
\hline Nantes LRT & 18.46 & 20.74 & 17.50 & 19.53 & 5.21 & 5.81 & 5.51 \\
\hline Paris LRT & 16.00 & 17.56 & 15.21 & 16.62 & 4.93 & 5.38 & 5.16 \\
\hline Rouen LRT & 20.52 & 21.88 & 19.41 & 20.63 & 5.39 & 5.73 & 5.56 \\
\hline Strasbourg LRT & 20.34 & 21.82 & 19.35 & 20.69 & 4.84 & 5.17 & 5.01 \\
\hline
\end{tabular}

\section{Conclusions}

Light rail's total journey time consists of LRV running time, dwell time, and signal delay. Generally, the signal delay takes 7 to 8 percent of light rail total journey time, dwell time 22 to 27 percent, and LRV running time 65 to 71 percent.

LRT systems should keep the number of passenger stops as low as possible, subject to passenger convenience, since light rail's operating speed decreases approximately linearly as the frequency of passenger stops increase.

LRT priority in at-grade crossing intersections will significantly improve LRT's operating speed. It is also desirable to eliminate pedestrian and normal road traffic induced delay by using a segregated tramway. 


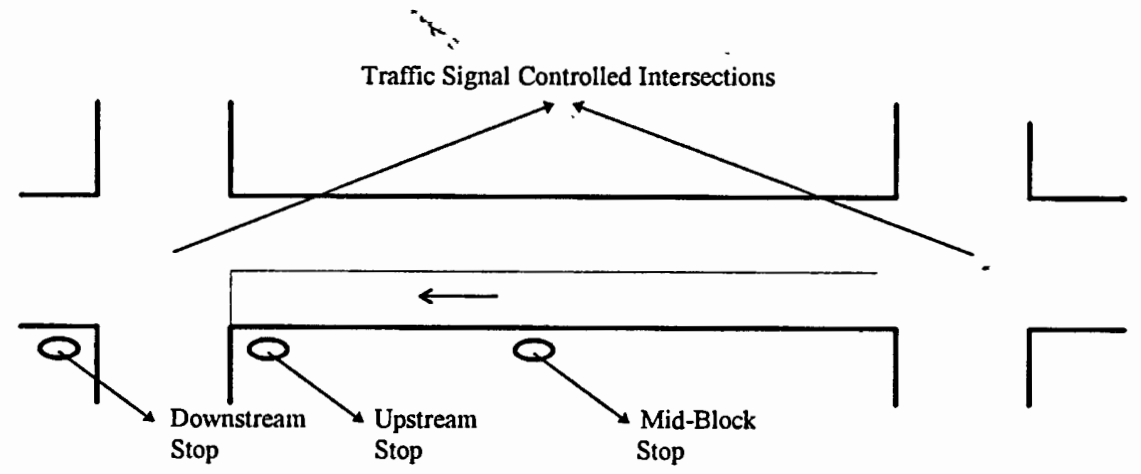

Figure 7. Relative locations of the LRT stops.

Significant differences in dwell time have been found between different light rail systems, and between peak and off-peak periods. Generally, the dwell time follows a log-normal distribution with the mean, $\mu$, in the range of 16 to 31 seconds in off-peak periods and 22 to 37 seconds in peak periods, according to the study based on the survey of the six light rail systems in France. LRT fare collection methods, LRV floor height (high or low), and door configurations are important factors of LRT dwell time on high passenger flow routes.

The results and findings in this paper can be used directly by LRT planners and operators in developing and assessing LRT operating and service changes and providing input to long-range planning procedures. Further, the LRT dwell time model is the essential component of LRT simulation models, which are increasingly considered by LRT planners and operators for system design and evaluation.

\section{Appendix A: Term Definitions}

The terms used in this paper have the following definitions:

\section{LRT:}

LRV(s):

Dwell Time:

Signal Delay:

Upstream Stop:
Light Rail Transit (sometimes termed Light Rapid Transit) Light Rail Vehicle(s)

LRV station stops for passenger boarding and alighting Delay of LRVs being stopped by the regular traffic signals LRT stops located upstream of the stop line at traffic signal controlled intersection (see Figure 7) 
Downstream Stop: LRT stops located downstream of the stop line at traffic signal controlled intersections (see Figure 7)

Middle Block Stop: LRT stops located in the middle area between two traffic signal controlled intersections (see Figure 7)

\section{Acknowledgments}

The authors wish to thank the local transport and LRT operation authorities in Grenoble, Lille, Nantes, Paris, Rouen, and Strasbourg for their kind support during our LRT operation characteristics survey.

\section{References}

Bushell, C. (Ed.). 1993. Jane's Urban Transport Systems 1992-93.

Ceder, A., and P. H. J. Marguier. 1985. Passenger Waiting Time at Transit Stops. Traffic Engineering + Control 26 (June): 327-329.

Cundill, M. A., and P. F. Watts. 1973. Bus Boarding and Alighting Times. Transport and Road Research Laboratory, Crowthorne, Laboratory Report 521.

Department of Transport. 1995. Light Rapid Transit (and Related) Systems. Buses and Taxis Division of the Department of Transport, London.

Fritz, M. S. 1983. Effect of Crowding on Light Rail Passenger Boarding Times. Transportation Research Record 908: 43-50.

Guenthner, R. P., and K. Hamat. 1988. Transit Dwell Time under Complex Fare Structures. Journal of Transportation Engineering (ASCE) 114(3) (May): 367-379.

Guenther, R. P., and K. C. Sinha. 1983. Modeling Bus Delays Due to Passenger Boarding and Alighting. Transportation Research Record 915: 7-12.

Kraft, W. H., and H. Deutschman. 1977. Bus Passenger Service Time Distributions. Transportation Research Record 625: 37-42.

Leivine, J. C., and G. W. Torng. 1994. Dwell-Time Effects of Low-Floor Bus Design. Journal of Transportation Engineering (ASCE) 120: 914-929.

Levinson, H. S. 1983. Analysing Transit Travel Time Performance. Transportation Research Record 915.

Lin, T. M., and N. H. M. Wilson. 1992. Dwell Time Relationships for Light Rail Systems. Transportation Research Board. Transportation Research Record 1361: 287-295. Manugistics, Inc. 1992. Statgraphics, Vol. 6. 
Marshall, L. F., H. S. Levinson, and L. C. Lennon. 1990. Bus Service Time and Capacities in Manhattan. Transporfation Research Record 1266: 189-196.

Urban Network News. December 1994/January 1995: 10.

Wu, J., and M. McDonald. 1996. TRGMSM: A Simulation Model for Light Rail Transit (LRT) At-Grade Crossing Design. Traffic Engineering and Control, Vol. 37, No. 3: 73-177.

Zografos, K. G., and H. S. Levinson. 1986. Passenger Service Times for a No-Fare Bus System. Transportation Research Record 1051: 42-47.

\section{About the Authors}

DR. JIANPING WU has six years of research experience on LRT operation, particularly at-grade operation at signalized traffic intersections, and developed the microscopic simulation model TRGMSM for LRT at-grade operation study. He has also been involved in other research activities including bus priority in London, fuzzy logic enhanced motorway traffic simulation, and route optimization for electric delivery vehicles. PRoFESSOR MIKE MCDONALD is Director of Transportation Research Group, University of Southampton, and has been responsible for over 100 research contracts for the Transport Research Laboratory, Department of Transport, Engineering Research Councils, the European Union, and other local and central government agencies. DR. NICK HouNSELL has 17 years of research experience in traffic management, public transport, and intelligent transportation systems, specializing in public transport priority and advanced traffic control systems, including substantial applications in London. He also has initiated major European projects on this topic, including leading a collaborative study into public transport priority in European Urban Traffic Control Systems. 